\title{
Endocrine targets of hypoxia-inducible factors
}

\author{
Hsiu-Chi Lee' ${ }^{1}$ and Shaw-Jenq Tsai1,2 \\ IInstitute of Basic Medical Sciences, College of Medicine, National Cheng Kung University, \\ Tainan, Taiwan \\ 2Department of Physiology, College of Medicine, National Cheng Kung University, Tainan, Taiwan
}

Correspondence should be addressed to S-J Tsai

Email

seantsai@mail.ncku.edu.tw

\begin{abstract}
Endocrine is an important and tightly regulated system for maintaining body homeostasis. Endocrine glands produce hormones, which are released into blood stream to guide the target cells responding to all sorts of stimulations. For maintaining body homeostasis, the secretion and activity of a particular hormone needs to be adjusted in responding to environmental challenges such as changes in nutritional status or chronic stress. Hypoxia, a status caused by reduced oxygen availability or imbalance of oxygen consumption/supply in an organ or within a cell, is a stress that affects many physiological and pathological processes. Hypoxic stress in endocrine organs is especially critical because endocrine glands control body homeostasis. Local hypoxia affects not only the particular gland but also the downstream cells/organs regulated by hormones secreted from this gland. Hypoxia-inducible factors (HIFs) are transcription factors that function as master regulators of oxygen homeostasis. Recent studies report that aberrant expression of HIFs in endocrine organs may result in the development and/or progression of diseases including diabetes, endometriosis, infertility and cancers. In this article, we will review recent findings in HIF-mediated endocrine organ dysfunction and the systemic syndromes caused by these disorders.
\end{abstract}

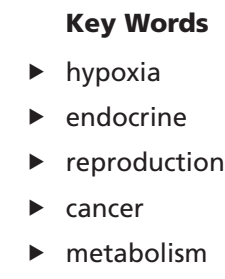

Journal of Endocrinology (2017) 234, R53-R65

\section{Introduction}

Oxygen is an important substrate/co-factor for energy production and many cellular biochemical reactions. Low oxygen condition (hypoxia) is considered a physiological and also a pathological situation, which involves in many biological processes such as organ development, stem cell maintenance, inflammation, aging, pulmonary disorder, cardiovascular disease, neuronal degeneration and cancer (Semenza 2007). Hypoxic effects can be accounted for by two distinct pathways: hypoxia-inducible factor (HIF)dependent and HIF-independent pathways. The HIFindependent pathway is mainly mediated by changing protein phosphorylation status (acute) and global transcription/translation efficiency (chronic), whereas the HIF-dependent pathway is regulated by altering specific target genes expression by HIF (chronic). HIF is the master transcriptional regulator, which modulates many cellular responses to enable cells to adapt to lower oxygen concentration. Besides the adaptive function of hypoxic stress and environmental changes, HIF is reported to play an important role in many diseases, such as circulatory disorder, metabolic disorder, inflammatory disease and cancer (Lin et al. 2014, Semenza 2014, Cummins et al. 2016).

The endocrine system consists of endocrine glands and circulatory system. The major endocrine glands include the pineal gland, pituitary gland, pancreas, 
ovaries, testes, thyroid glands, parathyroid glands, mammary glands, hypothalamus and adrenal glands. Since the discovery of leptin and other adipocytokines, adipose tissue is also considered as a nonclassical endocrine organ (Prins 2002). These glands produce and secrete hormones into the blood stream. Hormones act on target cells of specific organs via paracrine, autocrine or intracrine manners to modulate physiological functions. Hormone's effects are slow to initiate but prolonged in their response, lasting from a few hours up to weeks. In addition, as the hormonal effects usually involve different feedback mechanisms, the picture of endocrine disorders are quite complex. The disorders within the endocrine system may vary considerably in terms of symptoms. In general, endocrine disorders can be categorized as hypersecretion, hyposecretion, hyperresponsiveness and hyporesponsiveness. Molecular mechanisms responsible for endocrine disorder are complicated and remain largely unknown. Recent studies indicate that hypoxia is involved in hormone regulation, endocrine organ development and endocrine disorders. In this review, we summarize the current understanding about the pathological effects of hypoxia in endocrine organ with an emphasis on HIFdependent pathway.

A

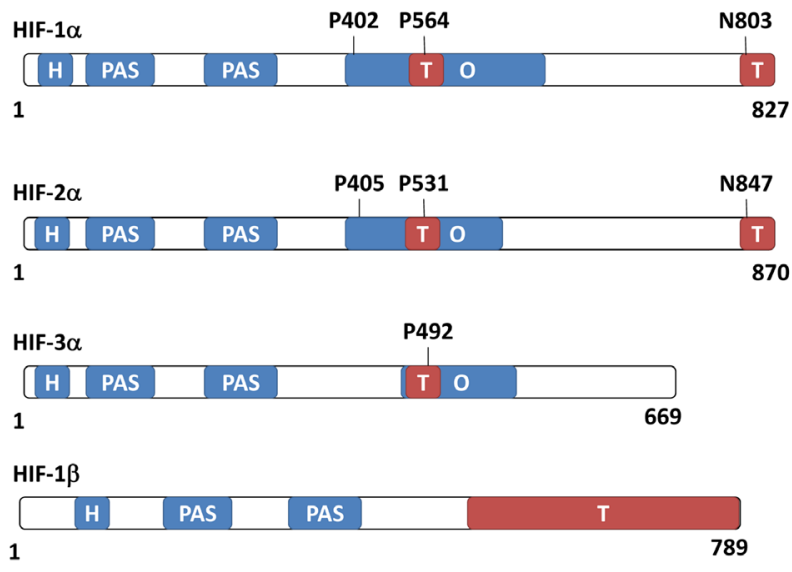

\section{Hypoxia and HIF regulation}

HIF is a heterodimeric protein that includes a stable $\beta$ subunit, also known as aryl hydrocarbon receptor nuclear translocator and an oxygen-sensitive $\alpha$ subunit. There are three members of HIF- $\alpha$ in mammal (Fig. 1). HIF- $1 \alpha$ and HIF- $2 \alpha$ proteins are critical for mediating the adaptive response of hypoxia, whereas HIF-3 $\alpha$ is usually considered as a negative regulator of HIF. HIF- $\alpha$ proteins form heterodimer with HIF- $1 \beta$ and then bind to hypoxia response element (HRE) of DNA to transactivate downstream target genes, which consist of at least 1000 genes (Manalo et al. 2005, Xia et al. 2009, Schodel et al. 2011). Both the $\alpha$ and $\beta$ subunits contain basic helixloop-helix (bHLH) domain for DNA binding, Per-ArntSim (PAS) domain for dimerization and transactivation domains (TADs) (Semenza 2000, Wu et al. 2015). Besides the common domains, the $\alpha$ subunit has a unique domain called oxygen-dependent degradation domain (ODDD), which contains two proline residues (Pro402 and Pro564 in HIF-1 $\alpha$ and Pro405 and Pro531 in HIF-2 $\alpha$ ) as target sites for hydroxylation by prolyl hydroxylase (Fig. 1). This specific modification generates a binding site for von Hippel-Lindau (VHL) protein, a component of the protein complex that possesses E3 ubiquitin ligase

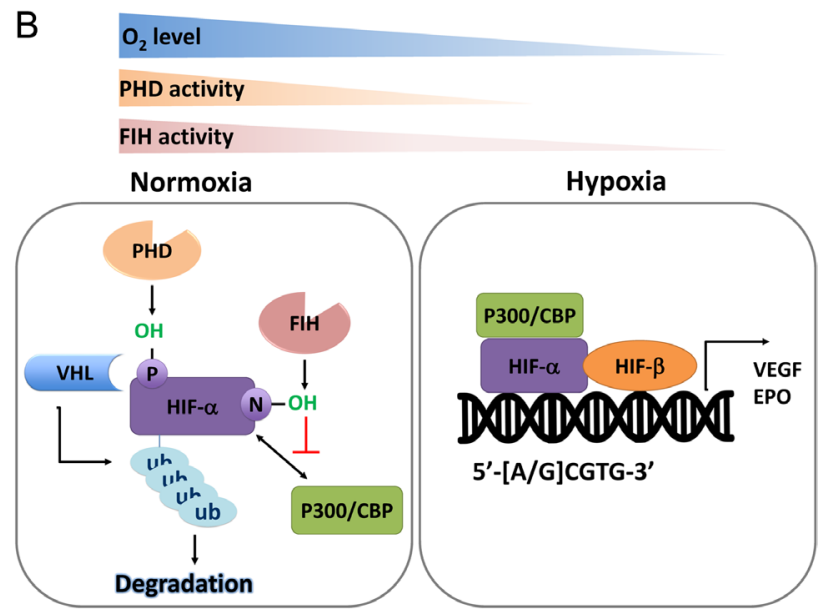

Figure 1

Schematic drawings show domain structure and regulation of HIFs. (A) Protein domain structures of HIF family members. Basic helix-loop-helix (H) domain is for DNA binding and Per-Arnt-Sim (PAS) domain is for dimerization. HIF- $\alpha$ contains oxygen-dependent degradation domain (O), which regulates HIF- $\alpha$ stability through the hydroxylation of proline (P) residues. HIF-1 $\alpha$ and HIF- $2 \alpha$ contain two transactivation domains (T), N-TAD and C-TAD. The asparagine $(\mathrm{N})$ residue is another amino acid that can be hydroxylated. The total length of each subunit is marked at the end of the domain structure. (B) Under normal oxygen tension, HIF- $\alpha$ subunit is hydroxylated by PHD, the hydroxylated proline residues is recognized and ubiquitylated by VHL and its associated ubiquitin ligase complex. Polyubiquitylated HIF- $\alpha$ subunit causes the protein degradation. HIF- $\alpha$ subunit binding with transcriptional co-activator p300/CBP complex is also inhibited by hydroxylation of asparagine residue by FIH. Under hypoxia, the enzymatic activity of PHDs and FIH are decreased. Therefore, HIF- $\alpha$ subunit escapes the degradation and associates with HIF- $\beta$ and the transcriptional co-activator in the nucleus. The heterodimer of HIF binds to consensus sequence HRE at the promoter region of HIF-responsive genes, such as VEGF and EPO, and initiates the gene transcription.

http://joe.endocrinology-journals.org DOI: 10.1530/JOE-16-0653
๑) 2017 Society for Endocrinology Printed in Great Britain
Published by Bioscientifica Ltd 
activity. Thus, HIF- $\alpha$ will be polyubiquitylated by VHL and then degraded by the 26S proteasome (Maxwell et al. 1999). Prolyl hydroxylase requires oxygen molecule, ferric ion and $\alpha$-ketoglutarate as cofactors to complete the enzymatic reaction. Thus, under hypoxic condition, the $\alpha$-subunit of HIF cannot be hydroxylated and the protein accumulates in the cytosol and translocates to nucleus.

Besides hydroxylation at the proline residues, HIF$\alpha$ also undergoes another major modification by factor inhibiting HIF-1 (FIH), which hydroxylates an asparagine residue (Asp803 in HIF-1 $\alpha$ and Asp847 in HIF-2 $\alpha$ ) in C-terminal TAD of HIF- $\alpha$. This modification prevents the interaction of TAD and transcriptional activator, p300 and CBP (Lando et al. 2002a,b, Ruas et al. 2002), and thus, attenuates the transcriptional activity of HIF. The enzymatic reaction catalyzed by FIH also requires oxygen molecule; therefore, FIH activity is decreased and the hydroxylation is reduced under hypoxia. As a result, the transcriptional activity of HIF is enhanced. Further, FIH also interacts with VHL and binds to the TAD of HIF- $1 \alpha$. The binding of FIH, VHL and HIF- $1 \alpha$ does not require the enzymatic activities of FIH or VHL. Instead, they form a ternary complex and recruits histone deacetylases to inhibit the transactivation activity of HIF- $1 \alpha$ (Mahon et al. 2001). It is suggested that this interaction may serve as a safeguarding system to prevent improper activation of HIF- $1 \alpha$ activity under normoxia. However, detailed mechanism regarding how histone deacetylase causes transcriptional repression needs further investigation.

\section{HIF signaling in endocrine disorders}

\section{Diabetes}

Type II diabetes mellitus (T2DM) is a global health problem, which is characterized by hyperglycemia and variable degrees of insulin deficiency and resistance. A growing body of evidences indicate that dysfunction of HIF signaling is involved in pathogenesis of T2DM. It has been found that HIF- $1 \beta$ expression is decreased in T2DM patients compared to normal controls and that $\beta$ cell-specific Hif-1 $\beta$-knockout mice displayed abnormal glucose metabolism and insulin secretion (Gunton et al. 2005). Similarly, $\beta$ cell-specific Hif- $1 \alpha$-knockout mice also exhibited glucose intolerance and $\beta$ cell dysfunction and developed severe glucose intolerance on a high-fat diet (Cheng et al. 2010). These data indicate that HIF is critical for maintaining normal function of $\beta$ cell and whole body glucose homeostasis (Fig. 2). Interestingly, $\beta$ cell-specific or pancreas-specific Vhl-knockout mice developed glucose intolerance with impaired insulin secretion. The impairment of insulin secretion in $\mathrm{Vhl}$ knockout mice is mediated by aberrant elevation of Hif- $1 \alpha$ as deletion of Hif- $1 \alpha$ in $\mathrm{Vhl}$-deficient $\beta$ cells restored glucose homeostasis (Cantley et al. 2009). Therefore, results from animal studies demonstrate that loss of function and aberrant gain of function of HIF signaling both result in reduced insulin secretion and glucose intolerance. These contradictory results provide a good example to illustrate the importance and complexity of HIF signaling in regulating insulin secretion and glucose homeostasis. Further studies are warranted to dissect the regulatory gene network downstream of HIF in contributing to the physiological and pathological functions of $\beta$ cell.

Adipose tissue is an endocrine organ, which synthesizes and releases adipocyte-derived polypeptides known as adipocytokines including pro-inflammatory cytokines (TNF- $\alpha$, IL-6, resistin, etc.), leptin and adiponectin to the circulation to regulate energy homeostasis. Dysfunction of adipose tissue due to obesity-induced hypoxia consequently leads to glucose intolerance and metabolic syndrome (Fig. 2). A handful of studies implicate that HIF- $1 \alpha$ and HIF- $2 \alpha$ are upregulated in obese adipose tissue and play critical roles in energy homeostasis. Inflammation, glucose intolerance and decreased liver sensitivity were observed in mice overexpressing constitutively active HIF-1 $\alpha$ in white adipose tissue (Halberg et al. 2009). In contrast, mice with adipocyte-specific Hif- $1 \alpha$ or Hif- $1 \beta$ knockout are more resistant to high-fat diet-induced weight gain, glucose intolerance and insulin insensitivity (Jiang et al. 2011, Krishnan et al. 2012). Hypoxic adipose tissue elicits hypersecretion of pro-inflammatory cytokines and hyposecretion of adiponectin, which results in increased infiltration of immune cells and decreased insulin sensitivity, respectively (Hosogai et al. 2007, Ye et al. 2007, Rausch et al. 2008, Halberg et al. 2009, Sun et al. 2013, Lee et al. 2014). Interestingly, recent finding reveals that HIF- $2 \alpha$ plays a protective role by promoting angiogenesis in adipose tissue (Garcia-Martin et al. 2016), a result similar to what was observed in pancreatic $\beta$ cells. Collectively, these studies provide the concept that the adipose tissue plays critical roles in maintaining body energy balance and is a druggable target for treating insulin resistance and metabolic diseases.

Liver is the major organ regulating not only glucose but also lipid metabolism. Hepatic glucose production and fatty acid $\beta$-oxidation are two important processes to generate ATP for brain, heart and adrenal medulla during
Published by Bioscientifica Ltd 


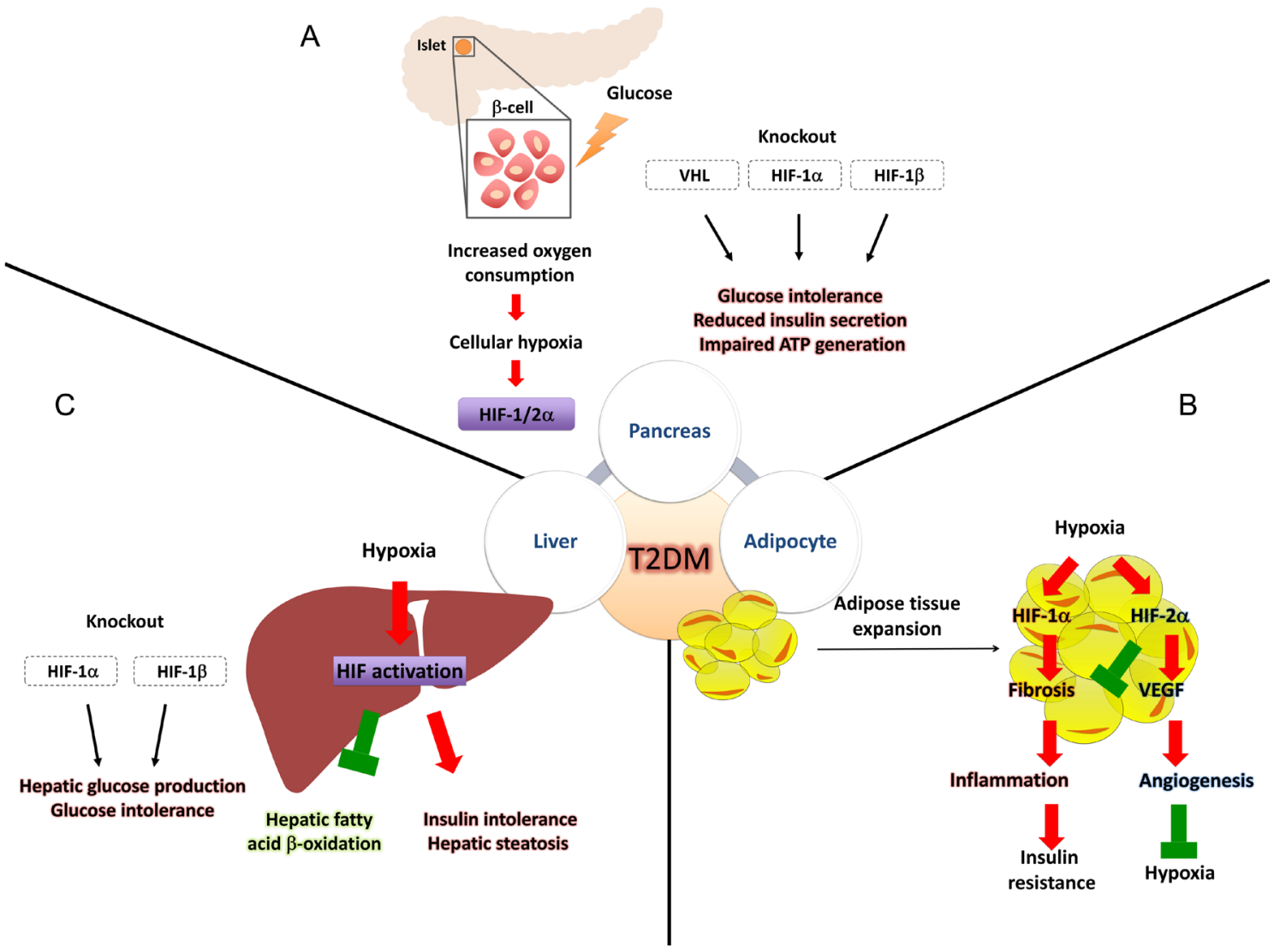

Figure 2

Regulation and function of HIF in endocrine organs associated with type 2 diabetes mellitus. (A) The effects of HIF signaling on glucose and lipid metabolism are more ambiguous, but there appears some link between hypoxia and T2DM development. The process of glucose metabolism consumes robust oxygen; thus, $\beta$-cells encounter cellular hypoxia condition that activates HIF-1/2 $\alpha$. Mice with $\beta$-cell-specific knockout Hif- $1 \alpha, H i f-1 \beta$, or Vh/ knockout show the impaired glucose metabolism features. (B) Adipose tissue expansion in obesity causes the hypoxic microenvironment. Hypoxia activates the HIF- $1 \alpha$ and HIF- $2 \alpha$ cascades. HIF-1 $\alpha$ increases adipose tissue fibrosis by upregulating collagen expression and promoting the crosslinking of collagens, which ultimately results in inflammation and insulin resistance. Conversely, HIF- $2 \alpha$ has protective effect through opposing the HIF- $1 \alpha$ pathway. Besides, HIF-2 $\alpha$ induces angiogenesis, which improves the oxygen level of adipose. (C) Hepatic lipid metabolism is a component of T2DM. Hypoxic hepatocytes, such as those in pericentral zone, are more involved in lipogenesis and repression of $\beta$-oxidation. In experimental obesity models, intermittent hypoxia exposure worsens the insulin intolerance and hepatic steatosis. Hepatocyte-specific Hif- $1 \alpha$ knockout mice fed with high-fat diet exhibit glucose intolerance. Hepatic ablation of Hif- $1 \beta$ in mice increases the hepatic glucose production and impairs the glucose tolerance.

fasting (Postic et al. 2004). In contrast, liver uptakes large amounts of blood glucose to store as glycogen or lipid (triacylglycerol) in the fed state. Oxygen tension is an important factor that controls hepatic glucose and lipid metabolism (Fig. 2). The flow of blood through the liver generates gradients of oxygen tension, which causes hepatocytes to become functionally different depending on their location along the portocentral axis (Hijmans et al. 2014). It is known that gluconeogenesis and $\beta$-oxidation take place in periportal hepatocytes (exposed to higher oxygen level), whereas glycolysis and lipogenesis occur in pericentral hepatocytes (exposed to lower oxygen level) (Guzman \& Castro 1989, Jungermann \& Thurman 1992). The distinct zonation of glucose/lipid metabolism indicates that the imbalance or inequality of oxygen concentrations may markedly influence energy homeostasis and disease development. It has been reported that expression of HIF- $1 \beta$ is decreased in liver of T2DM patients (Wang et al. 2009). By using liver-specific Hif-1 $\beta$-knockout mouse model, Wang and coworkers demonstrated that loss of HIF-1 $\beta$ function results in increased hepatic gluconeogenesis, increased lipogenic gene expression and low serum $\beta$-hydroxybutyrate, the characteristics of T2DM (Wang et al. 2009). Ochiai and coworkers reported that mice with hepatocyte-specific Hif-1 $\alpha$ knockout exhibited more severe impairment of glucose tolerance and insulin resistance than control littermates when fed with 
high-fat diet (Ochiai et al. 2011). These data demonstrate that HIFs exert a protective role in preventing highfat diet-induced liver steatosis. On the other hand, conditional knockout of $\mathrm{Vhl}$ or overexpression of Hif- $1 \alpha$ in hepatocytes cause hepatic lipid accumulation (Haase et al. 2001, Kim et al. 2006), suggesting HIF as a detrimental factor for liver disease and metabolic syndrome. The discrepancies between these distinct phenotypes are not known and warrant further investigation.

Taken together (Fig. 2), it is clear that HIFs, including HIF- $1 \alpha$, HIF- $2 \alpha$ and HIF- $1 \beta$ are necessary for maintaining whole body glucose homeostasis via regulating functions of $\beta$-cell, hepatocyte and adipocyte. Deficiency in either gene in any of these three endocrine tissues causes metabolic syndrome and ultimately results in T2DM. Equally importantly, aberrant overexpression of HIF- $\alpha$, especially HIF- $1 \alpha$, also results in glucose intolerance and metabolic syndrome. Thus, avoiding high-fat diet- or obesity-induced chronic inflammation to maintain HIF plasticity may be beneficial for glucose homeostasis.

\section{Thyroid disorder}

Thyroid hormone is another important mediator in regulating energy metabolism. The main hormone secreted by thyroid gland is the prohormone, thyroxine (T4). Once in the target tissue, T4 can be converted to 3,5,3'-triiodothyronine (T3, active form) or reverse T3 (rT3, inactive form). This action is modulated by different iodothyronine deiodinases. The activating deiodinase (D2) and inactivating deiodinase (D3) have been reported to regulate thyroid hormone during different conditions. Therefore, the regulation of D2 and D3 within target tissues dictates the function of thyroid hormone. The expression of D3 in the hypoxic tissues of human fetus and the ischemic tissues of critically ill patients suggests that hypoxia induces D3 expression (Richard et al. 1998, Huang et al. 2003, Peeters et al. 2003). The D3 expression is regulated through HIF-dependent pathway in hypoxicischemic heart disease using a rat model. Consequently, the elevated D3 decreases the level of T3 and impairs mitochondrial energy homeostasis, which might result in cell death (Simonides et al. 2008). Nevertheless, the study of hypoxia and thyroid hormone actions is still in its infancy, more investigations are needed in order to advance our understandings in how hypoxia/HIF regulates energy homeostasis through the metabolic effects of thyroid hormones.

\section{Male infertility}

In male reproduction, testosterone is responsible for spermatogenesis and the development of secondary sexual characteristics. Chronic hypobaric hypoxia decreases the luteinizing hormone and testosterone levels in men (Sawhney et al. 1985). Male rats exposed to chronic hypoxia and intermittent hypoxia result in changes in testicular morphology and loss of spermatogenic cells in all stages of the spermatogenic cycle (Farias et al. 2005). By monitoring the time course of endocrine change, it is suggested that the spermatogenic effect of chronic hypoxia may partially involve in changes of hypothalamuspituitary-gonad axis (Farias et al. 2008).

Local hypoxia in testis, mainly caused by varicocele and testicular torsion, also markedly reduces male fertility. Testicular torsion is caused by twisting of the spermatic cord, which reduces blood supply to the testicle and might lead to total loss of the testis. Varicocele is characterized by deficiency of the valves in the testicular venous system. The deficient valves cause exceeded blood pressure in venous system than that in the arterial system, which results in hypoxia in the seminiferous tubules of bilateral testes. In patients with varicocele, sperm production degenerates and then progresses to azoospermia (Gat et al. 2005), a phenomenon seen in up to $20 \%$ of male infertility situation. The levels of HIF- $1 \alpha$ and VEGF are elevated in the testis of male with varicocele and experimental varicocele rat model (Kilinc et al. 2004, Shiraishi \& Naito 2008). Interestingly, elevation of VEGF in testis is inversely correlated with total mobile sperm counts (Shiraishi \& Naito 2008), which suggests VEGF has a harmful effect in spermatogenesis. Indeed, it has been shown that overexpression of VEGF in the testis inhibits the proliferation of spermatogonia (Nalbandian et al. 2003) and causes infertility in transgenic mice (Korpelainen et al. 1998).

Testosterone production is also under the control of oxygen tension. Experimental animals exposed to chronic hypoxia exhibits a reduction in plasma and testicular testosterone concentrations (Farias et al. 2008, Madrid et al. 2013). This effect of testosterone reduction was also observed in patients suffering from obstructive sleep apnea (Liu et al. 2007) and in humans with longterm exposure to high altitude (Benso et al. 2007). Study using experimental animals reveals that the reduction in testosterone is likely due to a decrease in Leydig cell population (Farias et al. 2005). As testosterone is a potent paracrine factor for spermatogenesis, prolonged exposure to hypoxia may result in low sperm counts and infertility.

Published by Bioscientifica Ltd. 


\section{Female infertility}

Ovarian function is critical for female reproduction. Oocytes grow in the follicle surrounded by granulosa cells and thecal cells. The basement membrane forms a tight barrier between granulosa and thecal cells and thus blocks the blood vessel from infiltrating into the region where granulosa cells and oocyte reside. This structural barrier creates a hypoxic microenvironment for granulosa cells and germ cell. HIF has been postulated to involve in follicle development (Neeman et al. 1997) likely due to the hypoxic microenvironment in the follicle. However, it has become clear that expression of HIF- $1 \alpha$ is regulated by pituitary hormones instead of hypoxia in follicles. It has been shown that follicle-stimulating hormone (FSH) enhances HIF-1 $\alpha$ transcriptional activity, which augments FSH-induced upregulation of luteinizing hormone receptor, inhibin- $\alpha$ and VEGF to promote follicular differentiation to a preovulatory phenotype (Alam et al. 2004). HIF- $1 \alpha$ mRNA or protein was absent in pre-antral and antral follicles (Duncan et al. 2008) and become evident in the granulosa cells of preovulatory follicles in monkey (Duncan et al. 2008), porcine (Boonyaprakob et al. 2005) and mouse (Kim et al. 2009). In luteinized granulosa cells of human (van den Driesche et al. 2008) and bovine (Fadhillah et al. 2014), expression of HIF-1 $\alpha$ was also detected. These observations indicate that expression of HIF-1 $\alpha$ in granulosa cells is likely stimulated by luteinizing hormone (LH). Indeed, treatment of mouse granulosa cells with human chorionic gonadotropin (a hormone that also binds to LH receptor) but not hypoxia induces HIF- $1 \alpha$ mRNA (Tam et al. 2010). It is now clear that upregulation of HIF- $1 \alpha$ in the preovulatory granulosa cells is critical for ovulation as inhibition of HIF activity by echinomycin blocks ovulation in mice (Kim et al. 2009). Several genes involved in ovulation such as endothelin-2 ( $\mathrm{Na}$ et al. 2008, Wang et al. 2012), VEGF (Duncan et al. 2008), disintegrin and metalloproteinase with thrombospondinlike motifs-1 (Kim et al. 2009) are upregulated by HIF-1 in the preovulatory granulosa cells.

During ovulation, the basement membrane that separates granulosa cells and thecal cells brakes down and blood vessels infiltrate to facilitate the luteinization process. HIF-induced VEGF expression certainly is critical for this process. In addition, hypoxia also promotes progesterone production during luteinization (Fadhillah et al. 2014). In corpus luteum, HIF-1 $\alpha$ was highly expressed in the early corpus luteum and gradually declined as the corpus luteum aged (Boonyaprakob et al. 2005, Duncan et al. 2008). In early bovine luteal cells, hypoxia induces VEGF expression, which facilitates luteal development (Nishimura \& Okuda 2010). Interestingly, hypoxia inhibits progesterone production and promotes luteal cell apoptosis in mid-corpus luteum but not in the early corpus luteum (Nishimura et al. 2008, Nishimura \& Okuda 2010). These data indicate that hypoxia may exert distinct functions in bovine corpus luteum to regulate ovarian cycle and fertility.

\section{Endometriosis}

Endometriosis is a common gynecological disease, which causes severe pain and infertility. The etiology of endometriosis remains elusive; however, recent findings reveal that hypoxia plays critical roles in the development and progression of this disease (Fig. 3). Aberrant expression of HIF- $1 \alpha$ mRNA and protein has been found in endometriotic lesion, especially in the endometriotic stromal cells (Wu et al. 2007). Elevated level of HIF-1 $\alpha$ induces leptin production, which stimulates the proliferation of endometrial stromal cells ( $\mathrm{Wu}$ et al. 2007). Prostaglandin $\mathrm{E}_{2}\left(\mathrm{PGE}_{2}\right)$ is a major mediator in the pathogenesis of endometriosis, which stimulates steroidogenesis, angiogenesis and immune suppression (Wu et al. 2010 for review). Abnormal production of $\mathrm{PGE}_{2}$ is caused by overexpression of cyclooxygenase-2 (COX-2) in endometriotic stromal cells and peritoneal macrophages in women with endometriosis (Wu et al. 2002, 2005). Our studies demonstrate that hypoxia stimulates COX-2 expression through repression of dual-specificity phosphatase-2 (Wu et al. 2011) and induction of miR20a (Lin et al. 2012). Besides regulating $\mathrm{PGE}_{2}$-dependent pathogenesis, recent studies also show that hypoxia promotes angiogenesis via interleukin 8 (Hsiao et al. 2014), increases the migration ability of stromal cells via CD26/ dipeptidyl peptidase IV (Tan et al. 2014) and enhances autophagy via upregulating miR210 (Xu et al. 2016). These studies indicate that hypoxia promotes the development of endometriosis through various mechanisms. More importantly, a recent study demonstrates that hypoxia causes epigenome reprogramming by stimulating the degradation of DNA methyltransferase 1 mRNA, which results in altering the expression profile of some critical genes involved in the development/progression of endometriosis (Hsiao et al. 2015). This suggests that hypoxia may contribute to endometriosis by means of another layer of gene regulation. It would be interesting to investigate whether hypoxia also regulates RNA or histone modification to modulate gene expression epigenetically in endometriosis.

Published by Bioscientifica Ltd. 


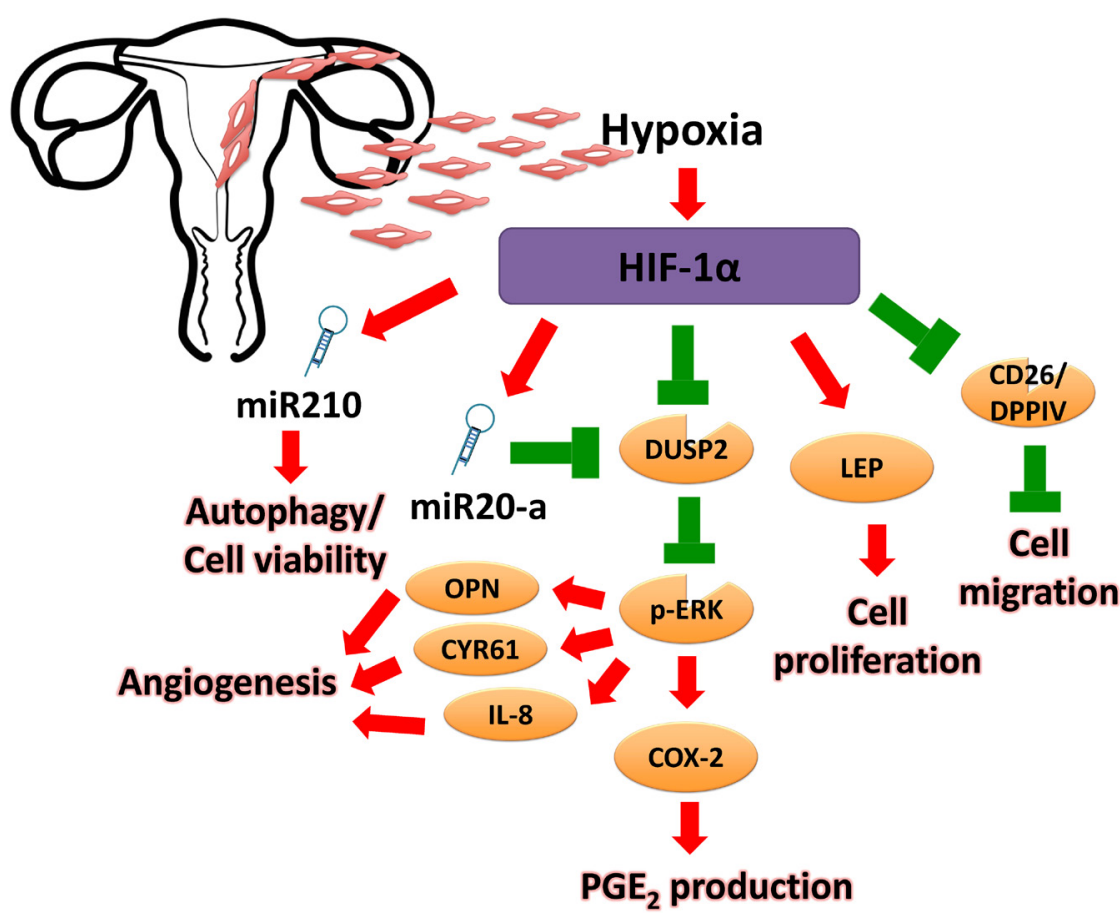

Figure 3

Hypoxia is involved in pathological processes of endometriosis. Retrograded endometrial fragments suffer from hypoxia before the vascular growth. Hypoxic condition stimulates prostaglandin- $\mathrm{E}_{2}\left(\mathrm{PGE}_{2}\right)$ production in ectopic cell by repression of dual-specificity phosphatase-2 (DUSP2) and induction of miR20-a. Activation of ERK further promotes angiogenesis by induction of angiogenic factors, such as, Cysteine-rich angiogenic inducer 61 (CYR61), osteopontin (OPN) and interleukin-8 (IL-8). Hypoxia induces leptin (LEP) and miR210 expression and thus promotes ectopic cell proliferation and autophagy/cell viability. In addition, hypoxia inhibits the migration inhibitor CD26/dipeptidyl peptidase IV (CD26/DPPIV) expression that increases the ability of cell migration.

\section{HIF signaling in endocrine tumors}

Endocrine gland tumor, in contrast to other solid cancers that normally only affect specific tissue or organ, always results in altering the physiological functions of whole body due to the complex feedback mechanisms of hormone. Hypoxia is known as a primary consequence of rapid cell proliferation in solid tumors because the oxygen molecule can only diffuse for $100-150 \mu \mathrm{m}$. Tumor hypoxia is strongly associated with tumor cell proliferation, malignancy and the resistance of therapy (Hockel \& Vaupel 2001). Considering the pathological functions of hypoxia in cancer have been reviewed in many articles, we will only discuss the unique effects of HIF in endocrine gland tumors-related systemic disorders in this section (Fig. 4).

\section{Pituitary tumor}

Pituitary adenomas are the most common intracranial neoplasms with the preference rate of one in ten thousand per year (Melmed 2008). Pituitary adenomas always accompany with some hormone disorder syndromes, such as acromegaly, Cushing's syndrome, hyperpituitarism and central diabetes insipidus. Although the genetic and molecular mechanisms responsible for the development and progression of pituitary adenomas remain largely unknown, recent studies reveal that hypoxia does play some critical roles in pituitary tumor malignancy. Like in any solid tumor, HIF- $1 \alpha$ is also elevated in pituitary adenoma. Overexpression of HIF$1 \alpha$ promotes hemorrhagic transformation in pituitary adenomas (Xiao et al. 2011), which usually causes sudden onset of headache, visual impairments, mental disorder and hormonal dysfunction, a disease known as pituitary apoplexy. The secretion of adrenocorticotropic hormone is reduced in patients with pituitary apoplexy, which results in lack of cortisol production (by adrenal gland). A decrease in cortisol may cause low blood pressure and low blood sugars, which is life-threatening and needs immediate medical attention. Elevation of HIF- $1 \alpha$ also reduces the sensitivity of temozolomide treatment by increasing autophagy process (Kun et al. 2015); thus, HIF- $1 \alpha$ knockdown or treatment with HIF- $1 \alpha$ inhibitor confers the temozolomide treatment sensitization in human adenomas through downregulation of O-6methylguanine-DNA methyltransferase expression (Chen et al. 2013). Taken together, these data suggest that HIF-1 may be a potential therapeutic target of pituitary adenomas and the related hormone disorder syndromes.

\section{Thyroid cancer}

Thyroid cancer is the most common malignancy of endocrine glands, which can be divided into papillary carcinomas (80\%), follicular carcinomas (10\%), medullary thyroid carcinomas (5-10\%), anaplastic carcinomas (1-2\%), primary thyroid lymphomas (rare) and primary

Published by Bioscientifica Ltd 
A

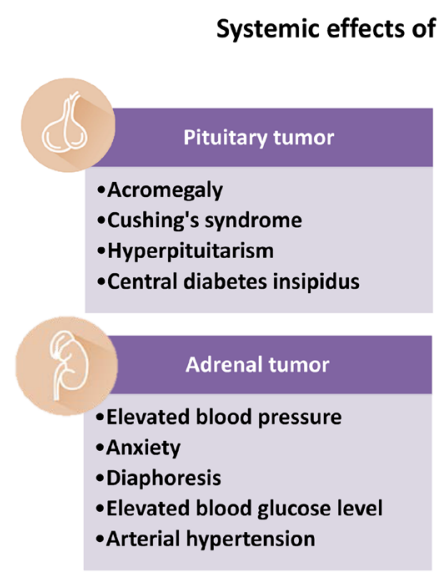

B

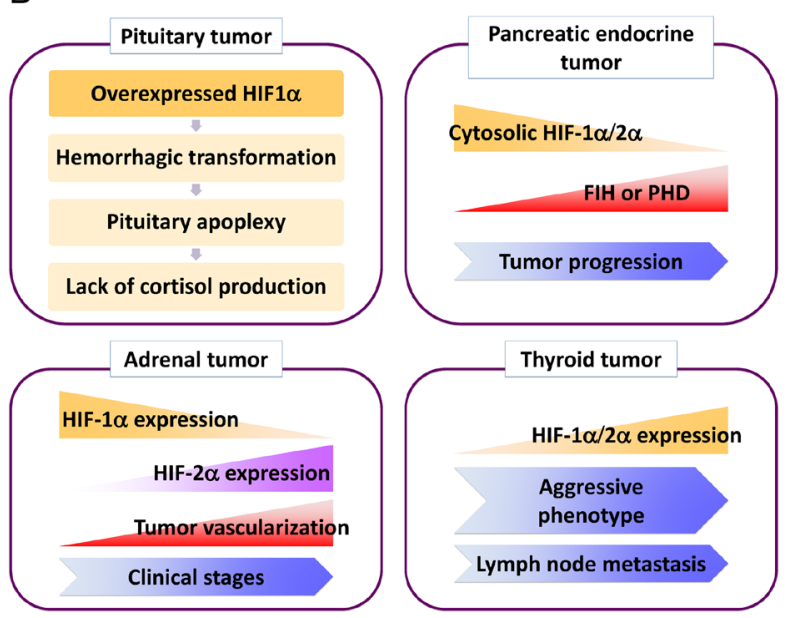

Figure 4

HIF expression levels and systemic effects of endocrine gland tumor. (A) A summary of disorders caused by endocrine tumors. The imbalance of hormone secretion due to endocrine glands tumors usually leads to alteration of physiological functions due to the complex feedback mechanisms of hormone. As a result, whole body homeostasis is disturbed and symptoms occur. (B) The levels of HIFs are correlated with the clinical observation in different types of endocrine tumors. PET, pancreatic endocrine tumor.

thyroid sarcomas (rare) (Kondo et al. 2006). HIF- $1 \alpha$ is expressed in both differentiated and dedifferentiated primary thyroid carcinomas and is positively associated with an aggressive disease phenotype (Burrows et al. 2010). Papillary carcinoma is a less malignant type of thyroid cancer with good prognosis; however, a small percentage of patients with papillary carcinoma still suffer from local invasion and metastasis. Animal study reveals that the invasive phenotype is accompanied with elevated level of HIF-1 $\alpha$, which can be blocked by HIF-1 $\alpha$ siRNA or inhibitor treatment (Mo et al. 2012). Other studies demonstrate that HIF-1 $\alpha$ and HIF- $2 \alpha$ expression is correlated with the lymph node metastasis (Wang et al. 2013, 2014). In medullary thyroid carcinoma, HIF-1 cooperates with mutant form proto-oncogene, rearranged during transfection (RET), to affect the expression of carbonic anhydrase 9 (CA9). The increased expression of CA9 in medullary thyroid carcinoma provides a highlight for targeting the RET oncoprotein and HIF-1 signaling pathway (Takacova et al. 2014). Anaplastic thyroid carcinoma is the most aggressive malignant thyroid tumors, which also exert highest level of HIF- $1 \alpha$. Recently, it was found that HIF- $1 \alpha$ induces the expression of IL-11, which then induces epithelialmesenchymal transition in anaplastic thyroid cancer cells via the PI3K/AKT/GSK3 $\beta$ pathway (Zhong et al. 2016). Take together, these findings suggest that both HIF- $1 \alpha$ and HIF- $2 \alpha$ promote thyroid cancer progression and metastasis even in the less malignant papillary carcinomas.

\section{Adrenal cancer}

Adrenal tumor is a benign or malignant neoplasm of adrenal gland. Malignant adrenal tumor includes neuroblastoma, adrenocortical carcinoma and some adrenal pheochromocytoma. Most adrenal pheochromocytomas and adrenocortical adenomas do not metastasize or invade nearby tissues, but cause health problems such as elevated blood pressure, anxiety, diaphoresis, elevated blood glucose level and arterial hypertension due to unbalancing hormones secretion or sympathetic nervous system hyperactivation. It has been reported that HIF$2 \alpha$ is overexpressed in pheochromocytoma and results in vascular growth (Favier et al. 2002). Overexpression of HIF- $2 \alpha$ is relatively common in VHL deficiency-related pheochromocytoma, whereas HIF- $1 \alpha$ is more frequent in succinate dehydrogenase-deficient pheochromocytoma (Pollard et al. 2006). Interestingly, it was reported that HIF$1 \alpha$ and HIF- $2 \alpha$ exert opposite effect in pheochromocytoma, suggesting the signaling pathways may be similar but the downstream effects are divergent (Qin et al. 2014). The distinct effects of HIF- $1 \alpha$ and HIF- $2 \alpha$ were also observed in adrenal neuroblastoma. Adrenal neuroblastoma is one of the common cancers in infant, which is an aggressive cancer of immature neuroblastic cells. HIF- $1 \alpha$ is negatively correlated with advanced clinical stage and tumor vascularization (Noguera et al. 2009). In contrast, HIF- $2 \alpha$ expression is well correlated with vascularized areas (Holmquist-Mengelbier et al. 2006) and poor prognosis (Pietras et al. 2009). Downregulation of miR-145 was found

Published by Bioscientifica Ltd. 
to be an upstream cause for the overexpression of HIF- $2 \alpha$ in adrenal neuroblastoma as forced expression of miR-145 reduces HIF-2 $\alpha$ protein level and suppresses tumor growth, invasion, angiogenesis and metastasis (Zhang et al. 2014). Collectively, these findings indicate that HIF- $2 \alpha$ but not HIF- $1 \alpha$ contributes to the pathogenesis of neuroblastoma and related endocrine disorder syndromes.

\section{Pancreatic endocrine tumor}

Pancreatic cancers can arise from the exocrine ( 95\%) and endocrine $(<5 \%)$ portions of the pancreas. Pancreatic endocrine tumors (PETs) are quite distinct from the usual form of pancreatic cancer. Pancreatic endocrine tumors can be divided into two general groups: functional and nonfunctional. Functional PETs ectopically secrete hormones to cause clinical symptoms such as ZollingerEllison syndrome (caused by aberrant secretion of gastrininduced peptic ulcer), hypoglycemia (caused by aberrant secretion of insulin), severe secretory diarrhea (caused by aberrant secretion of vasoactive intestinal peptide) and hyperglycemia/diabetes (caused by aberrant secretion of glucagon). In contrast, nonfunctional PETs do not secrete or secrete products that do not cause a clinical syndrome (Jensen et al. 2008). PETs are highly vascularized and exhibits distinct HIF expression pattern from other tumor (Marion-Audibert et al. 2003, Couvelard et al. 2005). The cytoplasmic HIF- $1 \alpha$ and $2 \alpha$ are expressed in normal islet cell, which is progressively lost with tumor progression (Couvelard et al. 2005). In contrast, the highly expressed HIF regulatory proteins, PHD and FIH are positively correlated with tumor metastases, tumor recurrence and prognosis (Couvelard et al. 2008). Furthermore, RSUME, a RWD-containing protein that stabilizes and enhances HIF- $1 \alpha$ expression is reduced in pancreatic endocrine tumors. In vivo orthotopic mice show that knockdown of RSUME enhances pancreatic endocrine tumor growth and liver metastasis (Wu et al. 2016). Collectively, these studies show that HIF expression and microvessel density are increased in well-differentiated pancreatic endocrine tumors and are positively correlated with overall survival rate. It also demonstrates that effect of HIF is significantly different in pancreatic endocrine tumor compared to other cancers.

\section{Conclusion and perspective}

A large body of evidence demonstrates that HIF-mediated signaling pathway involves in pathological progression of endocrine disorders and endocrine tumors. Different tissues have specific HIF expressions and downstream impacts. Some of the data suggest that HIF-1 $\alpha$ and HIF- $2 \alpha$ have synergistic effect, whereas some indicate the antagonistic effect. This should be taken into consideration when developing inhibitors targeting the HIF isoforms as the therapeutic drugs.

The other critical point that deserves attention is that although most of the cells in our body need oxygen to function normally, some tissues/cells are under 'normal' hypoxic condition (examples like pericentral hepatocytes, bone marrow, Sertoli cells of testis, granulosa and germ cells of ovarian follicles and islet cells of pancreas). These normal hypoxic tissues/cells are adaptive to hypoxic condition through specific HIF-mediated pathway. Therefore, inhibiting HIF activity would result in detrimental effect for these tissues. Therefore, it is generally accepted that HIF is not druggable and recent focus is shifted to target HIF downstream effectors to design more specific and less adverse compound as therapeutic approach. With the availability of large quantity of omics and metabolomics data and CRISPR/ Cas9 gene editing technique (Wiedenheft et al. 2012), it is now applicable to pinpoint the function of critical gene downstream of HIF in regulating specific biological process and manipulate it to alter or rectify the diseases caused by aberrant expression of this gene. One could expect that by employing these new techniques, diseases with complicated mechanisms such as hypoxia-mediated endocrine gland disorder can be manageable in the near future.

\section{Declaration of interest}

The authors declare that there is no conflict of interest that could be perceived as prejudicing the impartiality of this review.

\section{Funding}

This work was supported by grants from Ministry of Science and Technology, Taiwan (MOST 104-2320-B-006-036-MY3) and Top University grant of National Cheng Kung University (D105-35B03).

Author contribution statement

H C Lee drafted the manuscript. S J Tsai conceived this project and edited the manuscript.

\section{Acknowledgments}

The authors would like to thank all the contributing scientists to make this review article possible and to apologize to those whose works were not cited due to space limitation.

Published by Bioscientifica Ltd. 


\section{References}

Alam H, Maizels ET, Park Y, Ghaey S, Feiger ZJ, Chandel NS \& HunzickerDunn M 2004 Follicle-stimulating hormone activation of hypoxiainducible factor-1 by the phosphatidylinositol 3-kinase/AKT/Ras homolog enriched in brain (Rheb)/mammalian target of rapamycin (mTOR) pathway is necessary for induction of select protein markers of follicular differentiation. Journal of Biological Chemistry 279 19431-19440. (doi:10.1074/jbc.M401235200)

Benso A, Broglio F, Aimaretti G, Lucatello B, Lanfranco F, Ghigo E \& Grottoli S 2007 Endocrine and metabolic responses to extreme altitude and physical exercise in climbers. European Journal of Endocrinology 157 733-740. (doi:10.1530/EJE-07-0355)

Boonyaprakob U, Gadsby JE, Hedgpeth V, Routh PA \& Almond GW 2005 Expression and localization of hypoxia inducible factor-1alpha mRNA in the porcine ovary. Canadian Journal of Veterinary Research 69 215-222.

Burrows N, Resch J, Cowen RL, von Wasielewski R, Hoang-Vu C, West CM, Williams KJ \& Brabant G 2010 Expression of hypoxia-inducible factor 1 alpha in thyroid carcinomas. Endocrine-Related Cancer 17 61-72. (doi:10.1677/ERC-08-0251)

Cantley J, Selman C, Shukla D, Abramov AY, Forstreuter F, Esteban MA, Claret M, Lingard SJ, Clements M, Harten SK, et al. 2009 Deletion of the von Hippel-Lindau gene in pancreatic beta cells impairs glucose homeostasis in mice. Journal of Clinical Investigation 119 125-135.

Chen W, Xiao Z, Zhao Y, Huang L \& Du G 2013 HIF-1alpha inhibition sensitizes pituitary adenoma cells to temozolomide by regulating MGMT expression. Oncology Reports 30 2495-2501.

Cheng K, Ho K, Stokes R, Scott C, Lau SM, Hawthorne WJ, O'Connell PJ, Loudovaris T, Kay TW, Kulkarni RN, et al. 2010 Hypoxia-inducible factor-1alpha regulates beta cell function in mouse and human islets. Journal of Clinical Investigation 120 2171-2183. (doi:10.1172/ JCI35846)

Couvelard A, O'Toole D, Turley H, Leek R, Sauvanet A, Degott C, Ruszniewski P, Belghiti J, Harris AL, Gatter K, et al. 2005 Microvascular density and hypoxia-inducible factor pathway in pancreatic endocrine tumours: negative correlation of microvascular density and VEGF expression with tumour progression. British Journal of Cancer 92 94-101. (doi:10.1038/sj.bjc.6602245)

Couvelard A, Deschamps L, Rebours V, Sauvanet A, Gatter K, Pezzella F, Ruszniewski P \& Bedossa P 2008 Overexpression of the oxygen sensors PHD-1, PHD-2, PHD-3, and FIH Is associated with tumor aggressiveness in pancreatic endocrine tumors. Clinical Cancer Research 14 6634-6639. (doi:10.1158/1078-0432.CCR-07-5258)

Cummins EP, Keogh CE, Crean D \& Taylor CT 2016 The role of HIF in immunity and inflammation. Molecular Aspects of Medicine 47-48 24-34. (doi:10.1016/j.mam.2015.12.004)

Duncan WC, van den Driesche S \& Fraser HM 2008 Inhibition of vascular endothelial growth factor in the primate ovary up-regulates hypoxia-inducible factor-1alpha in the follicle and corpus luteum. Endocrinology 149 3313-3320. (doi:10.1210/en.2007-1649)

Fadhillah, Yoshioka S, Nishimura R \& Okuda K 2014 Hypoxia promotes progesterone synthesis during luteinization in bovine granulosa cells. Journal of Reproduction and Development 60 194-201. (doi:10.1262/ jrd.2014-014)

Farias JG, Bustos-Obregon E, Orellana R, Bucarey JL, Quiroz E \& Reyes JG 2005 Effects of chronic hypobaric hypoxia on testis histology and round spermatid oxidative metabolism. Andrologia 37 47-52. (doi:10.1111/j.1439-0272.2004.00651.x)

Farias JG, Bustos-Obregon E, Tapia PJ, Gutierrez E, Zepeda A, Juantok C, Cruz G, Soto G, Benites J \& Reyes JG 2008 Time course of endocrine changes in the hypophysis-gonad axis induced by hypobaric hypoxia in male rats. Journal of Reproduction and Development 54 18-21. (doi:10.1262/jrd.19046)

Favier J, Plouin PF, Corvol P \& Gasc JM 2002 Angiogenesis and vascular architecture in pheochromocytomas: distinctive traits in malignant tumors. American Journal of Pathology 161 1235-1246. (doi:10.1016/ S0002-9440(10)64400-8)

Garcia-Martin R, Alexaki VI, Qin N, Rubin de Celis MF, Economopoulou M, Ziogas A, Gercken B, Kotlabova K, Phieler J, Ehrhart-Bornstein $\mathrm{M}$, et al. 2016 Adipocyte-specific hypoxia-inducible factor 2 alpha deficiency exacerbates obesity-induced brown adipose tissue dysfunction and metabolic dysregulation. Molecular and Cellular Biology 36 376-393. (doi:10.1128/MCB.00430-15)

Gat Y, Zukerman Z, Chakraborty J \& Gornish M 2005 Varicocele, hypoxia and male infertility. Fluid Mechanics analysis of the impaired testicular venous drainage system. Human Reproduction 20 2614-2619. (doi:10.1093/humrep/dei089)

Gunton JE, Kulkarni RN, Yim S, Okada T, Hawthorne WJ, Tseng YH, Roberson RS, Ricordi C, O'Connell PJ, Gonzalez FJ, et al. 2005 Loss of ARNT/HIF1beta mediates altered gene expression and pancreaticislet dysfunction in human type 2 diabetes. Cell 122 337-349. (doi:10.1016/j.cell.2005.05.027)

Guzman M \& Castro J 1989 Zonation of fatty acid metabolism in rat liver. Biochemical Journal 264 107-113. (doi:10.1042/bj2640107)

Haase VH, Glickman JN, Socolovsky M \& Jaenisch R 2001 Vascular tumors in livers with targeted inactivation of the von Hippel-Lindau tumor suppressor. PNAS 98 1583-1588. (doi:10.1073/pnas.98.4.1583)

Halberg N, Khan T, Trujillo ME, Wernstedt-Asterholm I, Attie AD, Sherwani S, Wang ZV, Landskroner-Eiger S, Dineen S, Magalang UJ, et al. 2009 Hypoxia-inducible factor 1alpha induces fibrosis and insulin resistance in white adipose tissue. Molecular and Cellular Biology 29 4467-4483. (doi:10.1128/MCB.00192-09)

Hijmans BS, Grefhorst A, Oosterveer MH \& Groen AK 2014 Zonation of glucose and fatty acid metabolism in the liver: mechanism and metabolic consequences. Biochimie 96 121-129. (doi:10.1016/j. biochi.2013.06.007)

Hockel M \& Vaupel P 2001 Tumor hypoxia: definitions and current clinical, biologic, and molecular aspects. Journal of the National Cancer Institute 93 266-276. (doi:10.1093/jnci/93.4.266)

Holmquist-Mengelbier L, Fredlund E, Lofstedt T, Noguera R, Navarro S, Nilsson H, Pietras A, Vallon-Christersson J, Borg A, Gradin K, et al. 2006 Recruitment of HIF-1alpha and HIF-2alpha to common target genes is differentially regulated in neuroblastoma: HIF2alpha promotes an aggressive phenotype. Cancer Cell 10 413-423. (doi:10.1016/j.ccr.2006.08.026)

Hosogai N, Fukuhara A, Oshima K, Miyata Y, Tanaka S, Segawa K, Furukawa S, Tochino Y, Komuro R, Matsuda M, et al. 2007 Adipose tissue hypoxia in obesity and its impact on adipocytokine dysregulation. Diabetes 56 901-911. (doi:10.2337/db06-0911)

Hsiao KY, Chang N, Lin SC, Li YH \& Wu MH 2014 Inhibition of dual specificity phosphatase- 2 by hypoxia promotes interleukin-8mediated angiogenesis in endometriosis. Human Reproduction 29 2747-2755. (doi:10.1093/humrep/deu255)

Hsiao KY, Wu MH, Chang N, Yang SH, Wu CW, Sun HS \& Tsai SJ 2015 Coordination of AUF1 and miR-148a destabilizes DNA methyltransferase 1 mRNA under hypoxia in endometriosis. Molecular Human Reproduction 21 894-904. (doi:10.1093/molehr/gav054)

Huang SA, Dorfman DM, Genest DR, Salvatore D \& Larsen PR 2003 Type 3 iodothyronine deiodinase is highly expressed in the human uteroplacental unit and in fetal epithelium. Journal of Clinical Endocrinology and Metabolism 88 1384-1388. (doi:10.1210/jc.2002021291)

Jensen RT, Berna MJ, Bingham DB \& Norton JA 2008 Inherited pancreatic endocrine tumor syndromes: advances in molecular pathogenesis, diagnosis, management, and controversies. Cancer 113 1807-1843. (doi:10.1002/cncr.23648)

Jiang C, Qu A, Matsubara T, Chanturiya T, Jou W, Gavrilova O, Shah YM \& Gonzalez FJ 2011 Disruption of hypoxia-inducible factor 1 in adipocytes improves insulin sensitivity and decreases adiposity in high-fat diet-fed mice. Diabetes 60 2484-2495. (doi:10.2337/db110174) 
Jungermann K \& Thurman RG 1992 Hepatocyte heterogeneity in the metabolism of carbohydrates. Enzyme 46 33-58.

Kilinc F, Kayaselcuk F, Aygun C, Guvel S, Egilmez T \& Ozkardes H 2004 Experimental varicocele induces hypoxia inducible factor-1alpha, vascular endothelial growth factor expression and angiogenesis in the rat testis. Journal of Urology 172 1188-1191. (doi:10.1097/01. ju.0000135455.97627.15)

Kim WY, Safran M, Buckley MR, Ebert BL, Glickman J, Bosenberg M, Regan M \& Kaelin WG Jr 2006 Failure to prolyl hydroxylate hypoxiainducible factor alpha phenocopies VHL inactivation in vivo. EMBO Journal 25 4650-4662. (doi:10.1038/sj.emboj.7601300)

Kim J, Bagchi IC \& Bagchi MK 2009 Signaling by hypoxia-inducible factors is critical for ovulation in mice. Endocrinology $1503392-3400$. (doi:10.1210/en.2008-0948)

Kondo T, Ezzat S \& Asa SL 2006 Pathogenetic mechanisms in thyroid follicular-cell neoplasia. Nature Reviews Cancer 6 292-306. (doi:10.1038/nrc1836)

Korpelainen EI, Karkkainen MJ, Tenhunen A, Lakso M, Rauvala H, Vierula M, Parvinen M \& Alitalo K 1998 Overexpression of VEGF in testis and epididymis causes infertility in transgenic mice: evidence for nonendothelial targets for VEGF. Journal of Cell Biology 143 1705-1712. (doi:10.1083/jcb.143.6.1705)

Krishnan J, Danzer C, Simka T, Ukropec J, Walter KM, Kumpf S, Mirtschink P, Ukropcova B, Gasperikova D, Pedrazzini T, et al. 2012 Dietary obesity-associated Hif1alpha activation in adipocytes restricts fatty acid oxidation and energy expenditure via suppression of the Sirt2-NAD+ system. Genes and Development 26 259-270. (doi:10.1101/ gad.180406.111)

Kun Z, Yuling Y, Dongchun W, Bingbing X, Xiaoli L \& Bin X 2015 HIF-1alpha inhibition sensitized pituitary adenoma cells to temozolomide by regulating presenilin 1 expression and autophagy. Technology in Cancer Research and Treatment 15 NP95-NP104. (doi:10.1177/1533034615618834)

Lando D, Peet DJ, Gorman JJ, Whelan DA, Whitelaw ML \& Bruick RK $2002 a$ FIH-1 is an asparaginyl hydroxylase enzyme that regulates the transcriptional activity of hypoxia-inducible factor. Genes and Development 16 1466-1471. (doi:10.1101/gad.991402)

Lando D, Peet DJ, Whelan DA, Gorman JJ \& Whitelaw ML $2002 b$ Asparagine hydroxylation of the HIF transactivation domain a hypoxic switch. Science 295 858-861. (doi:10.1126/science.1068592)

Lee YS, Kim JW, Osborne O, Oh da Y, Sasik R, Schenk S, Chen A, Chung H, Murphy A, Watkins SM, et al. 2014 Increased adipocyte O2 consumption triggers HIF-1alpha, causing inflammation and insulin resistance in obesity. Cell 157 1339-1352. (doi:10.1016/j. cell.2014.05.012)

Lin SC, Wang CC, Wu MH, Yang SH, Li YH \& Tsai SJ 2012 Hypoxiainduced microRNA-20a expression increases ERK phosphorylation and angiogenic gene expression in endometriotic stromal cells. Journal of Clinical Endocrinology and Metabolism 97 E1515-E1523. (doi:10.1210/jc.2012-1450)

Lin SC, Liao WL, Lee JC \& Tsai SJ 2014 Hypoxia-regulated gene network in drug resistance and cancer progression. Experimental Biology and Medicine 239 779-792. (doi:10.1177/1535370214532755)

Liu PY, Caterson ID, Grunstein RR \& Handelsman DJ 2007 Androgens, obesity, and sleep-disordered breathing in men. Endocrinology Metabolism Clinics of North America 36 349-363. (doi:10.1016/j. ecl.2007.03.002)

Madrid E, Reyes JG, Hernandez B, Garcia JM, San Martin S, Olivero P, Crespo PV \& Parraga M 2013 Effect of normobaric hypoxia on the testis in a murine model. Andrologia 45 332-338. (doi:10.1111/ and.12019)

Mahon PC, Hirota K \& Semenza GL 2001 FIH-1: a novel protein that interacts with HIF-1alpha and VHL to mediate repression of HIF-1 transcriptional activity. Genes and Development 15 2675-2686. (doi:10.1101/gad.924501)
Manalo DJ, Rowan A, Lavoie T, Natarajan L, Kelly BD, Ye SQ, Garcia JG \& Semenza GL 2005 Transcriptional regulation of vascular endothelial cell responses to hypoxia by HIF-1. Blood 105 659-669. (doi:10.1182/ blood-2004-07-2958)

Marion-Audibert AM, Barel C, Gouysse G, Dumortier J, Pilleul F, Pourreyron C, Hervieu V, Poncet G, Lombard-Bohas C, Chayvialle JA, et al. 2003 Low microvessel density is an unfavorable histoprognostic factor in pancreatic endocrine tumors. Gastroenterology 125 1094-1104. (doi:10.1016/S00165085(03)01198-3)

Maxwell PH, Wiesener MS, Chang GW, Clifford SC, Vaux EC, Cockman ME, Wykoff CC, Pugh CW, Maher ER \& Ratcliffe PJ 1999 The tumour suppressor protein VHL targets hypoxia-inducible factors for oxygendependent proteolysis. Nature 399 271-275. (doi:10.1038/20459)

Melmed S 2008 Update in pituitary disease. Journal of Clinical Endocrinology and Metabolism 93 331-338. (doi:10.1210/jc.2007-1409)

Mo JH, Choi IJ, Jeong WJ, Jeon EH \& Ahn SH 2012 HIF-1alpha and HSP90: target molecules selected from a tumorigenic papillary thyroid carcinoma cell line. Cancer Science 103 464-471. (doi:10.1111/j.13497006.2011.02181.x)

Na G, Bridges PJ, Koo Y \& Ko C 2008 Role of hypoxia in the regulation of periovulatory EDN2 expression in the mouse. Canadian Journal of Physiology and Pharmacology 86 310-319. (doi:10.1139/Y08-025)

Nalbandian A, Dettin L, Dym M \& Ravindranath N 2003 Expression of vascular endothelial growth factor receptors during male germ cell differentiation in the mouse. Biology of Reproduction 69 985-994. (doi:10.1095/biolreprod.102.013581)

Neeman M, Abramovitch R, Schiffenbauer YS \& Tempel C 1997 Regulation of angiogenesis by hypoxic stress: from solid tumours to the ovarian follicle. International Journal of Experimental Pathology $\mathbf{7 8}$ 57-70. (doi:10.1046/j.1365-2613.1997.d01-247.x)

Nishimura R \& Okuda K 2010 Hypoxia is important for establishing vascularization during corpus luteum formation in cattle. Journal of Reproduction and Development 56 110-116. (doi:10.1262/jrd.09162E)

Nishimura R, Komiyama J, Tasaki Y, Acosta TJ \& Okuda K 2008 Hypoxia promotes luteal cell death in bovine corpus luteum. Biology of Reproduction 78 529-536. (doi:10.1095/biolreprod.107.063370)

Noguera R, Fredlund E, Piqueras M, Pietras A, Beckman S, Navarro S \& Pahlman S 2009 HIF-1alpha and HIF-2alpha are differentially regulated in vivo in neuroblastoma: high HIF-1alpha correlates negatively to advanced clinical stage and tumor vascularization. Clinical Cancer Research 15 7130-7136. (doi:10.1158/1078-0432.CCR09-0223)

Ochiai D, Goda N, Hishiki T, Kanai M, Senoo-Matsuda N, Soga T, Johnson RS, Yoshimura Y \& Suematsu M 2011 Disruption of HIF-1alpha in hepatocytes impairs glucose metabolism in diet-induced obesity mice. Biochemical and Biophysical Research Communications 415 445-449. (doi:10.1016/j.bbrc.2011.10.089)

Peeters RP, Wouters PJ, Kaptein E, van Toor H, Visser TJ \& Van den Berghe G 2003 Reduced activation and increased inactivation of thyroid hormone in tissues of critically ill patients. Journal of Clinical Endocrinology and Metabolism 88 3202-3211. (doi:10.1210/jc.2002022013)

Pietras A, Hansford LM, Johnsson AS, Bridges E, Sjolund J, Gisselsson D, Rehn M, Beckman S, Noguera R, Navarro S, et al. 2009 HIF-2alpha maintains an undifferentiated state in neural crest-like human neuroblastoma tumor-initiating cells. PNAS 106 16805-16810. (doi:10.1073/pnas.0904606106)

Pollard PJ, El-Bahrawy M, Poulsom R, Elia G, Killick P, Kelly G, Hunt T, Jeffery R, Seedhar P, Barwell J, et al. 2006 Expression of HIF-1alpha, HIF-2alpha (EPAS1), and their target genes in paraganglioma and pheochromocytoma with VHL and SDH mutations. Journal of Clinical Endocrinology and Metabolism 91 4593-4598. (doi:10.1210/jc.20060920) http://joe.endocrinology-journals.org

DOI: $10.1530 / J O E-16-0653$
(C) 2017 Society for Endocrinology Printed in Great Britain 
Postic C, Dentin R \& Girard J 2004 Role of the liver in the control of carbohydrate and lipid homeostasis. Diabetes and Metabolism 30 398-408. (doi:10.1016/S1262-3636(07)70133-7)

Prins JB 2002 Adipose tissue as an endocrine organ. Best Practice and Research Clinical Endocrinology and Metabolism 16 639-651. (doi:10.1053/beem.2002.0222)

Qin N, de Cubas AA, Garcia-Martin R, Richter S, Peitzsch M, Menschikowski M, Lenders JW, Timmers HJ, Mannelli M, Opocher G, et al. 2014 Opposing effects of HIF1alpha and HIF2alpha on chromaffin cell phenotypic features and tumor cell proliferation: insights from MYC-associated factor X. International Journal of Cancer 135 2054-2064. (doi:10.1002/ijc.28868)

Rausch ME, Weisberg S, Vardhana P \& Tortoriello DV 2008 Obesity in C57BL/6J mice is characterized by adipose tissue hypoxia and cytotoxic T-cell infiltration. International Journal of Obesity $\mathbf{3 2}$ 451-463. (doi:10.1038/sj.ijo.0803744)

Richard K, Hume R, Kaptein E, Sanders JP, van Toor H, De Herder WW, den Hollander JC, Krenning EP \& Visser TJ 1998 Ontogeny of iodothyronine deiodinases in human liver. Journal of Clinical Endocrinology and Metabolism 83 2868-2874. (doi:10.1210/ jc.83.8.2868)

Ruas JL, Poellinger L \& Pereira T 2002 Functional analysis of hypoxiainducible factor-1 alpha-mediated transactivation. Identification of amino acid residues critical for transcriptional activation and/or interaction with CREB-binding protein. Journal of Biological Chemistry 277 38723-38730. (doi:10.1074/jbc.M205051200)

Sawhney RC, Chhabra PC, Malhotra AS, Singh T, Riar SS \& Rai RM 1985 Hormone profiles at high altitude in man. Andrologia 17 178-184. (doi:10.1111/j.1439-0272.1985.tb00983.x)

Schodel J, Oikonomopoulos S, Ragoussis J, Pugh CW, Ratcliffe PJ \& Mole DR 2011 High-resolution genome-wide mapping of HIF-binding sites by ChIP-seq. Blood 117 e207-e217. (doi:10.1182/blood-2010-10314427)

Semenza GL 2000 HIF-1 and human disease: one highly involved factor. Genes and Development 14 1983-1991.

Semenza GL 2007 Hypoxia-inducible factor 1 (HIF-1) pathway. Science STKE $2007 \mathrm{~cm} 8$.

Semenza GL 2014 Oxygen sensing, hypoxia-inducible factors, and disease pathophysiology. Annual Review of Pathology 9 47-71. (doi:10.1146/ annurev-pathol-012513-104720)

Shiraishi K \& Naito K 2008 Involvement of vascular endothelial growth factor on spermatogenesis in testis with varicocele. Fertility and Sterility 90 1313-1316. (doi:10.1016/j.fertnstert.2007.08.030)

Simonides WS, Mulcahey MA, Redout EM, Muller A, Zuidwijk MJ, Visser TJ, Wassen FW, Crescenzi A, da-Silva WS, Harney J, et al. 2008 Hypoxia-inducible factor induces local thyroid hormone inactivation during hypoxic-ischemic disease in rats. Journal of Clinical Investigation 118 975-983.

Sun K, Halberg N, Khan M, Magalang UJ \& Scherer PE 2013 Selective inhibition of hypoxia-inducible factor 1alpha ameliorates adipose tissue dysfunction. Molecular and Cellular Biology 33 904-917. (doi:10.1128/MCB.00951-12)

Takacova M, Bullova P, Simko V, Skvarkova L, Poturnajova M, Feketeova L, Babal P, Kivela AJ, Kuopio T, Kopacek J, et al. 2014 Expression pattern of carbonic anhydrase IX in Medullary thyroid carcinoma supports a role for RET-mediated activation of the HIF pathway. American Journal of Pathology 184 953-965. (doi:10.1016/j. ajpath.2014.01.002)

Tam KK, Russell DL, Peet DJ, Bracken CP, Rodgers RJ, Thompson JG \& Kind KL 2010 Hormonally regulated follicle differentiation and luteinization in the mouse is associated with hypoxia inducible factor activity. Molecular and Cellular Endocrinology 327 47-55. (doi:10.1016/j.mce.2010.06.008)

Tan CW, Lee YH, Tan HH, Lau MS, Choolani M, Griffith L \& Chan JK 2014 CD26/DPPIV down-regulation in endometrial stromal cell migration in endometriosis. Fertility and Sterility 102 167.e169-177. e169. (doi:10.1016/j.fertnstert.2014.04.001)

van den Driesche S, Myers M, Gay E, Thong KJ \& Duncan WC 2008 HCG up-regulates hypoxia inducible factor- 1 alpha in luteinized granulosa cells: implications for the hormonal regulation of vascular endothelial growth factor A in the human corpus luteum. Molecular Human Reproduction 14 455-464. (doi:10.1093/molehr/gan040)

Wang XL, Suzuki R, Lee K, Tran T, Gunton JE, Saha AK, Patti ME, Goldfine A, Ruderman NB, Gonzalez FJ, et al. 2009 Ablation of ARNT/HIF1beta in liver alters gluconeogenesis, lipogenic gene expression, and serum ketones. Cell Metabolism 9 428-439. (doi:10.1016/j.cmet.2009.04.001)

Wang Z, Zhang Z, Wu Y, Chen L, Luo Q, Zhang J, Chen J, Luo Z, Huang X \& Cheng Y 2012 Effects of echinomycin on endothelin-2 expression and ovulation in immature rats primed with gonadotropins. Experimental and Molecular Medicine 44 615-621. (doi:10.3858/ emm.2012.44.10.070)

Wang N, Luo HJ, Yin GB, Dong CR, Xu M, Chen GG \& Liu ZM 2013 Overexpression of HIF-2alpha, TWIST, and CXCR4 is associated with lymph node metastasis in papillary thyroid carcinoma. Clinical and Developmental Immunology 2013 589423. (doi:10.1155/2013/413928)

Wang N, Dong CR, Jiang R, Tang C, Yang L, Jiang QF, Chen GG \& Liu ZM 2014 Overexpression of HIF-1alpha, metallothionein and SLUG is associated with high TNM stage and lymph node metastasis in papillary thyroid carcinoma. International Journal of Clinical and Experimental Pathology 7 322-330.

Wiedenheft B, Sternberg SH \& Doudna JA 2012 RNA-guided genetic silencing systems in bacteria and archaea. Nature 482 331-338. (doi:10.1038/nature10886)

Wu MH, Sun HS, Lin CC, Hsiao KY, Chuang PC, Pan HA \& Tsai SJ 2002 Distinct mechanisms regulate cyclooxygenase- 1 and -2 in peritoneal macrophages of women with and without endometriosis. Molecular Human Reproduction 8 1103-1110. (doi:10.1093/molehr/8.12.1103)

Wu MH, Wang CA, Lin CC, Chen LC, Chang WC \& Tsai SJ 2005 Distinct regulation of cyclooxygenase- 2 by interleukin-1beta in normal and endometriotic stromal cells. Journal of Clinical Endocrinology and Metabolism 90 286-295. (doi:10.1210/jc.2004-1612)

Wu MH, Chen KF, Lin SC, Lgu CW \& Tsai SJ 2007 Aberrant expression of leptin in human endometriotic stromal cells is induced by elevated levels of hypoxia inducible factor-1alpha. American Journal of Pathology 170 590-598. (doi:10.2353/ajpath.2007.060477)

Wu MH, Lu CW, Chuang PC \& Tsai SJ 2010 Prostaglandin E2: the master of endometriosis? Experimental Biology and Medicine 235 668-677. (doi:10.1258/ebm.2010.009321)

Wu MH, Lin SC, Hsiao KY \& Tsai SJ 2011 Hypoxia-inhibited dualspecificity phosphatase- 2 expression in endometriotic cells regulates cyclooxygenase-2 expression. Journal of Pathology 225 390-400. (doi:10.1002/path.2963)

Wu D, Potluri N, Lu J, Kim Y \& Rastinejad F 2015 Structural integration in hypoxia-inducible factors. Nature $\mathbf{5 2 4}$ 303-308. (doi:10.1038/ nature14883)

Wu Y, Tedesco L, Lucia K, Schlitter AM, Garcia JM, Esposito I, Auernhammer CJ, Theodoropoulou M, Arzt E, Renner U, et al. 2016 RSUME is implicated in tumorigenesis and metastasis of pancreatic neuroendocrine tumors. Oncotarget 7 57878-57893.

Xia X, Lemieux ME, Li W, Carroll JS, Brown M, Liu XS \& Kung AL 2009 Integrative analysis of HIF binding and transactivation reveals its role in maintaining histone methylation homeostasis. PNAS 106 4260-4265. (doi:10.1073/pnas.0810067106)

Xiao Z, Liu Q, Zhao B, Wu J \& Lei T 2011 Hypoxia induces hemorrhagic transformation in pituitary adenomas via the HIF-1alpha signaling pathway. Oncology Reports 26 1457-1464.

Xu TX, Zhao SZ, Dong M \& Yu XR 2016 Hypoxia responsive miR-210 promotes cell survival and autophagy of endometriotic cells in hypoxia. European Review for Medical and Pharmacological Sciences 20 399-406. http://joe.endocrinology-journals.org

DOI: 10.1530/JOE-16-0653
(C) 2017 Society for Endocrinology Printed in Great Britain 
Ye J, Gao Z, Yin J \& He Q 2007 Hypoxia is a potential risk factor for chronic inflammation and adiponectin reduction in adipose tissue of ob/ob and dietary obese mice. American Journal of Physiology: Endocrinology and Metabolism 293 E1118-E1128. (doi:10.1152/ ajpendo.00435.2007)

Zhang H, Pu J, Qi T, Qi M, Yang C, Li S, Huang K, Zheng L \& Tong Q 2014 MicroRNA-145 inhibits the growth, invasion, metastasis and angiogenesis of neuroblastoma cells through targeting hypoxiainducible factor 2 alpha. Oncogene 33 387-397. (doi:10.1038/ onc.2012.574)

Zhong Z, Hu Z, Jiang Y, Sun R, Chen X, Chu H, Zeng M \& Sun C 2016 Interleukin-11 promotes epithelial-mesenchymal transition in anaplastic thyroid carcinoma cells through PI3K/Akt/GSK3beta signaling pathway activation. Oncotarget 7 59652-59663.

Received in final form 18 April 2017

Accepted 28 April 2017

Accepted Preprint published online 28 April 2017
() 2017 Society for Endocrinology Printed in Great Britain
Published by Bioscientifica Ltd 